\title{
Chillida y la poesía
}

\author{
Clara Janés
}

Recibido: 14.01.2020 — Aceptado: 10.02.2020

\section{Title / Titre / Titolo}

Chillida and Poetry

Chillida et la poésie

Chillida e la poesia

\section{Resumen / Abstract / Résumé / Riassunto}

Para Chillida la palabra poesía tiene ante todo un sentido genésico, y recurre a ella precisamente al tratar de la creación: «¿No son la construcción y la poesía componentes esenciales de todas las artes?» $\mathrm{Si}$ para el físico Minkowski, cuando el poeta habla «devuelve al ser la energía de un origen» (algo intangible relacionado con el tiempo), la construcción (vinculada al espacio) nos acerca al decir de Heidegger: «Ser obra es establecer un mundo». De ahí que construcción y poesía abarquen juntas ambas cosas. Chillida no tarda en entrar en contacto con Heidegger y hace con él un intenso libro titulado El arte y el espacio, pero pronto hace también un homenaje al poeta Jorge Guillén, seducido por su verso: «Lo profundo es el aire». Por otra parte, estando la poesía vinculada a la música, donde, dice Walter Pater, «no se distingue entre materia y forma», Chillida se acerca también a ella. Como consecuencia, junto a su homenaje a San Juan de la Cruz, hallamos el dedicado a Juan Sebastián Bach. Así sus obras pueden titularse: Rumor de límites, Espacios sonoros, Música de las esferas, Vibraciones...

For Chillida, the word poetry has above all a genesic sense, and he resorts to it precisely when dealing with creation: «Aren't construction and poetry essential components of all the arts?» If, for the physicist Minkowski, when the poet speaks «he returns to being the energy of an origin» (something intangible related to time), construction (linked to space) brings us closer when Heidegger says: «To be work is to establish a world». That's why construction and poetry encompass both things. Chillida soon makes contact with Heidegger and writes an intense book entitled El arte y el espacio (Art and Space), but he also pays homage to the poet Jorge Guillén, seduced by his verse: «The deepest thing is air». On the other hand, since poetry is linked to music, where, says Walter Pater, «no distinction is made between matter and form», Chillida also approaches it. As a consequence, together with his homage to Saint John of the Cross, we find the one dedicated to John Sebastian Bach. Thus his works can be called: Rumour of Limits, Sound Spaces, Music of the Spheres, Vibrations...

Pour Chillida, le mot poésie a avant tout un sens génésique, et il y recourt précisément lorsqu'il s'agit de création : «La construction et la poésie ne sont-elles pas des composantes essentielles de tous les arts» $\mathrm{Si}$, pour le physicien Minkowski, lorsque le poète parle «il revient à être l'énergie d'une origine» (quelque chose d'intangible lié au temps), la construction (liée à l'espace) nous rapproche lorsque Heidegger dit : «Être travail, c'est établir un monde». C'est pourquoi la construction et la poésie couvrent ensemble les deux choses. Chillida prend rapidement contact avec Heidegger et écrit avec lui un livre intense intitulé El arte y el espacio (L'art et l'espace), mais il rend également hommage au poète Jorge Guillén, séduit par son vers : «Le plus profond, c'est l'air». D'autre part, comme la poésie est liée à la musique, où, selon Walter Pater, «aucune distinction n'est faite entre la matière et la forme», Chillida l'aborde également. Par conséquent, avec son hommage à Saint Jean de la Croix, nous trouvons celui dédié à Jean Sébastien Bach. Ainsi, ses œuvres peuvent s'appeler : Rumeur des limites, Espaces sonores, Musique des sphères, Vibrations...

Per Chillida la parola poesia ha soprattutto un senso genesico, e vi ricorre proprio quando si tratta della creazione: «La costruzione e la poesia non sono componenti essenziali di tutte le arti?» Se per il fisico Minkowski, quando il poeta parla «torna ad essere l'energia di un'origine» (qualcosa di intangibile legato al tempo), la costruzione (legata allo spazio) ci avvicina a ciò che Heidegger afferma: «Essere opera è creare un mondo». Ecco perché la costruzione e la poesia comprendono entrambe le cose. Chillida entra presto in contatto con Heidegger e scrive un libro intenso intitolato El arte y el espacio (Arte e spazio), ma rende anche omaggio al poeta Jorge Guillén, sedotto dal suo verso: «La cosa più profonda è l'aria». D'altra parte, poiché la poesia è legata alla musica, dove, afferma Walter Pater, «non si fa distinzione tra materia e forma», anche Chillida si avvicina ad essa. Di conseguenza, insieme al suo omaggio a San Giovanni della Croce, troviamo quello dedicato a Giovanni Sebastiano Bach. Così le sue opere possono essere chiamate: Rumour of Limits, Sound Spaces, Music of the Spheres, Vibrations...

\section{Palabras clave / Keywords I Mots-clé / Parole chiave}

Espacio, tiempo, música, materia, forma, visible, invisible, Chillida, Walter Pater, Juan Sebastián Bach, Heidegger, Minkowski. Space, time, music, matter, form, visible, invisible, Chillida,

Walter Pater, Juan Sebastián Bach, Heidegger, Minkowski. Espace, temps, musique, matière, forme, visible, invisible, Chillida, Walter Pater, Juan Sebastián Bach, Heidegger, Minkowski. Spazio, tempo, musica, materia, forma, visibile, invisibile, Chillida, Walter Pater, Juan Sebastián Bach, Heidegger, Minkowski. 
Se me ha pedido que hable de la relación de Eduardo Chillida con la poesía y con mucho gusto he aceptado e intentaré hacerlo.

El sentido que la palabra «poesía» tenía para Chillida no es fundamentalmente el que remite a un poema, sino el que evoca su carácter genésico. Poesía viene del griego poiesis, que significa crear. Esto no quiere decir que Chillida no colaborara con poetas. Podemos, pues, pensar que, respecto a la poesía, estableció una relación doble. En efecto, por un lado la consideraba parte fundamental de la creación, y, por otro llevó a cabo distintos libros de artista, entre los cuales dos inspirados en autores griegos antiguos, Esquilo y Parménides, algunos en colaboración con filósofos o ensayistas, como Heidegger o Cioran, otros con poetas, Guillén, Ullán, Edmond Jabès, Valente o yo misma, cada uno con su propia singularidad. Tal vez por tratarse de los primeros, resultan especialmente reveladores los que hizo con Jorge Guillén y con Martin Heidegger. Probablemente a través de ellos, Chillida da el salto al otro plano del sentido que, para él, tiene la palabra poesía, es decir, el sentido genésico. Este salto, a su vez, lo sitúa a él mismo en las dos coordenadas entre las que se mueve la vida: espacio y tiempo. José Antonio Fernández Ordóñez - ingeniero y colaborador suyo fundamentalapuntala dicha realidad al afirmar que Chillida «mira la naturaleza bajo la integridad, que es la vida» (Fernández Ordóñez, 39). Su obra, por tanto, tenderá a ambas cosas, espacio y tiempo. Y siendo así que una creación escultórica se dirige al espacio, él buscará cómo incorporar también el tiempo. En este marco centraré mis palabras.

Eduardo Chillida, haciendo gala del talante con el que san Agustín definió al hombre, como un ser que se hace preguntas — «nos interrogantes», dijo—, escribió un breve libro titulado precisamente Preguntas, libro que puede darnos pistas para nuestro cometido, pues en él, al formular su concepto de creación artística, recurre precisamente a la poesía. Dice así: «¿No son la construcción y la poesía componentes esenciales de todas las artes?»(Fernández Ordóñez, 9). Esta pregunta comporta, de hecho, una afirmación implícita: en toda obra de arte hay que tener en cuenta dos aspectos, uno que rebasa al artista, el creativo —llámese intuición, inspiración o iluminación-, y otro que depende de él, lo cual despierta un eco lejano del aserto de Baudelaire: «Si la inspiración llega me encontrará siempre trabajando».

Las mencionadas palabras de Chillida — «No son la construcción y la poesía componentes esenciales de todas las artes?»— inducen, de hecho, a su vez, a otras dos preguntas: ¿Qué es poesía?, y ¿qué es construcción?

Para responder a la primera, acudamos a Aristóteles que afirmó que la voz es aire y ritmo. La mera respiración supone ya —en muchos casos - un leve sonido, sonido que, como tal, se desarrolla en el tiempo. En cuanto ese sonido se articula y se une al ritmo surge el germen de la poesía, que como consecuencia se desarrolla también en el tiempo. Y la poesía, por otra parte, se caracteriza por captar y expresar algo no plenamente manifiesto.

En muchas civilizaciones es precisamente la voz la que da origen a la creación. Por ello Gaston Bachelard, en su Poética del espacio, recuerda las palabras del físico Minkowski para el cual cuando habla el poeta «devuelve al ser la energía de un origen» (Bachelard, 44).

La poesía, pues, repito, se relaciona con el tiempo y con lo intuido no manifiesto. Veamos ahora la otra cara de la definición del arte hecha por Chillida: la construcción. ¿Qué es construcción? Por un momento atendamos a unas palabras de Martin Heidegger: «Ser obra es establecer un mundo» (Heiddeger, 9). Esta obra, por supuesto, puede ser poética, pero poiesis, ya lo he dicho, es la palabra griega que significa creación. Muy cercana a ella, «construcción» requiere de materia, de un ente tangible, que se sitúa en el espacio. En estos dos extremos, lo tangible y el espacio, se sitúa la escultura.

Eduardo Chillida, pues, tiene que enfrentarse, por de pronto, con la materia y con el espacio, y, dado que entra en contacto con Heidegger, lleva a cabo con él un intenso libro, El arte y el espacio (Die Kunst und der Raum). La identificación entre ambos es perfecta: se trata de la parte tangible del arte, la dotada de un desarrollo visual. 


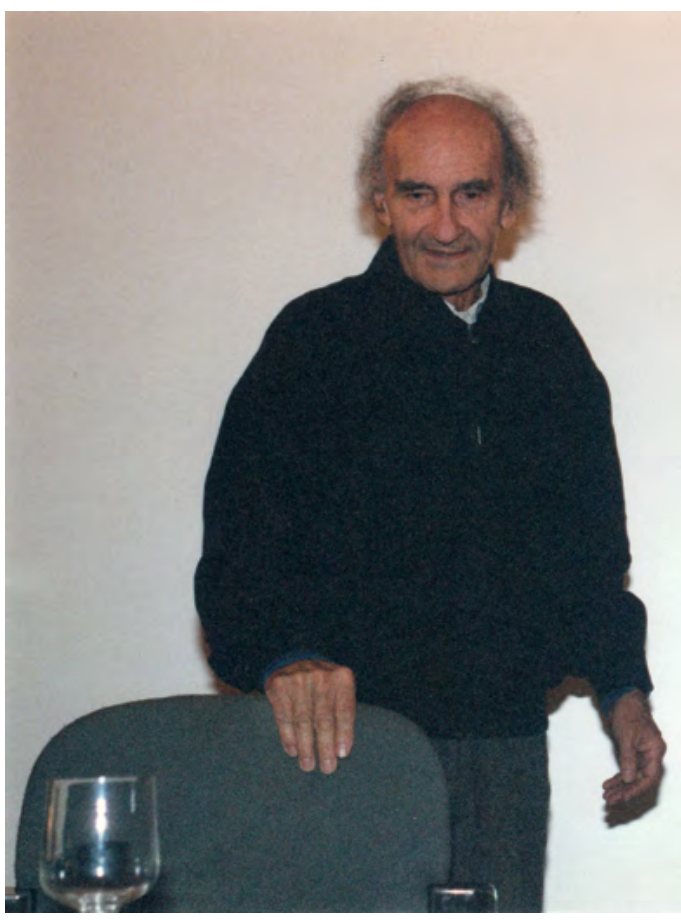

Volvamos por un momento a la poesía y a la pregunta: «¿No son la construcción y la poesía componentes esenciales de todas las artes?». En esta elocución no se define ni concreta siquiera un estilo, pero la sensibilidad de Chillida, al descubrir los versos de Jorge Guillén, entre los cuales figura: «lo profundo es el aire», se abrirá a una confluencia. El entusiasmo que despierta en él esta visión del elemento espacial irrebatible -el aire- le impulsa a realizar libros y esculturas. Dice el poema entero de Guillén:

Soy, más, estoy. Respiro.

Lo profundo es el aire.

La realidad me inventa,

Soy su leyenda. ¡Salve!

¿Qué más, junto al modo de definir el aire-espacio, ha tocado a Chillida en estos versos? Algo relacionado con el tiempo: constituyen una exaltación del presente. Se trata, pues, de la contraposición ya mencionada espacio-tiempo, que él quiere diseñar también con su obra, aunque su trabajo, por naturaleza, sea espacial. Sin duda esta es la clave de la importancia que da al instan-

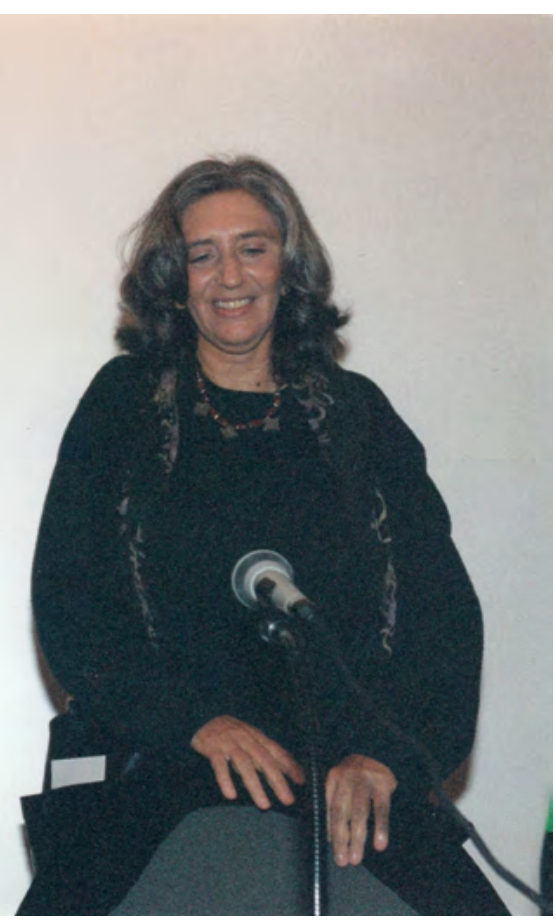

te, como con lucidez ha visto Ana María Rabe, la cual nos descubre el vericueto, casi podríamos decir el juego mágico, mediante el cual el escultor logra introducir el tiempo en su creación. Y, para subrayarlo, cita unas palabras suyas: «El límite es el verdadero protagonista del espacio, como el presente, otro límite, es el verdadero protagonista del tiempo» (Rabe, 248). Y Rabe añade algo fundamental: «El espacio frenado, desde luego, no está vencido. Es más bien un elemento lento que guarda un impulso de fuga, un ímpetu que hace resonar los límites. Esta idea da origen a aquellas obras de Chillida, cuyos títulos evocan asociaciones auditivas, como Hierros del temblor, o las que llevan el nombre Rumor de limites», es decir, se incautan de sonido.

Espacio, pues, naturalmente, por un lado, y sonido (poesía), es decir tiempo, por otro. La poesía además está impregnada de música, en sí misma tiempo, por lo cual, como puntualizó Walter Pater, «en ella no se distingue entre materia y forma». Acaso Chillida, buscando igualmente esa perfección, llega a asimilar ambas artes, escultura y música, y, como otros creadores, por ejemplo el músico Federico Mompou, define el suyo como un recomenzar. Dice concretamente: «Escultura y mú- 
sica tienen el mismo espacio sonoro el cual, sin cesar, es recomenzado» (cit. en Barañano, 69).

\section{¿A qué poesía y a qué música se acerca Chillida?}

La obra de Jorge Guillén se titula Cántico como reconocimiento a los versos de san Juan de la Cruz. También Chillida, como veremos, se acerca a san Juan. En cuanto a la música, en su libro ya mencionado Preguntas (Fernández Ordóñez, 21) leemos:

$$
\begin{aligned}
& \text { Juan Sebastián Bach saludo } \\
& \text { moderno como las olas } \\
& \text { antiguo como la mar } \\
& \text { siempre nunca diferente } \\
& \text { pero nunca siempre igual. }
\end{aligned}
$$

Es decir, Chillida asocia al músico que valora por encima de todos, al lugar donde se halla hoy la que es acaso su obra magna, el Peine del viento, del que afirmó: «Este lugar es el origen de todo... El verdadero lugar de estas obras es él. Yo lo he descubierto y le he hecho un homenaje. Me enamoré de ese lugar mucho antes de saber que iba a hacer algo en él —antes de ser escultor... ni siquiera había terminado el bachiller... podría tener catorce años pensando de dónde vienen las olas...» (Chamorro Romero).

Construcción y poesía, sí, esto es el arte para Chillida. Y su obra es poesía. Y es construcción. Y aquel que habla de la construcción y hace con él ese libro tan hermoso, que se titula Die Kunst und der Raum, Martin Heidegger, define, a su vez, con precisión el arte a través de la poesía: «Todo arte es como dejar acontecer el advenimiento de la verdad del ente en cuanto tal, y por lo mismo es en esencia poesía» (Heiddeger, 87). Y prosigue: «El decir proyectante es poesía: el decir del mundo y la tierra, el decir del campo y su lucha, y con ello del lugar de toda cercanía y lejanía de los dioses. La poesía es el decir de la desocultación del ente» (Heiddeger, 88). «La poesía está tomada aquí en una unidad interna tan esencial con el habla y la palabra, que debe quedar abierta la cuestión de si el arte en todas sus especies [...] agotan a la poesía. Pero la esencia de la poesía es instauración de la verdad.
[...] El lenguaje mismo es Poesía en el sentido esencial» (Heiddeger, 89).

Emilio Lledó, en Fidelidad a Grecia (43), nos recuerda que somos el animal que habla, el homo loquens, el que «se hace al hablan», se hace persona, y que persona era la máscara teatral que, gracias al espacio que generaba entre ella y la boca del actor, la palabra resonaba. Hemos de resonar en los demás, insiste. Y añade que, con la música, despertamos un universo de «consonancias».

Consonancias, resonancias, rumores... Chillida los incorpora también en su obra: Rumor de límites, Espacios sonoros, Gran temblor, Música de las esferas, Vibraciones...

«El artista es el origen de la obra. La obra es el origen del artista», escribió también Heidegger (56), entre cuyos libros figura Senderos del bosque. Y veamos como, aunque la confluencia entre él y Chillida se basa ante todo en ese construir que se vincula con la poesía, también el filósofo escribió algunos poemas. Precisamente a ese título, Senderos del bosque, nos recuerda uno que dice así:

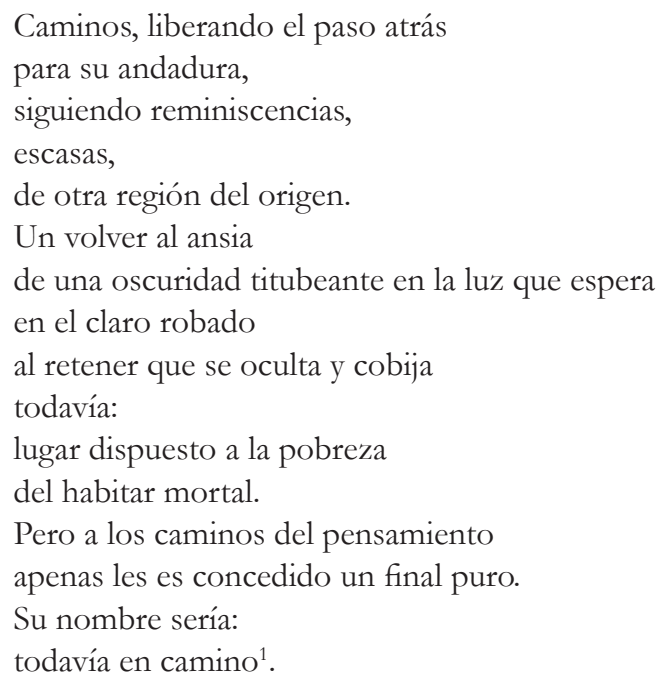

El camino impulsa a seguir, pero Jorge Guillén escribió: «Las palabras resuenan con frescura de Génesis». No se equivocó Minkowski que, como hemos visto, dijo que el poeta otorga a la palabra «la energía de un origen». Para Jorge Guillén, Chillida realizó unas planchas basadas en la blancura del alba. A partir de

${ }^{1}$ https://www.faz.net/aktuell/feuilleton/botho-strauss-heideggers-gedichte1576360.html. 


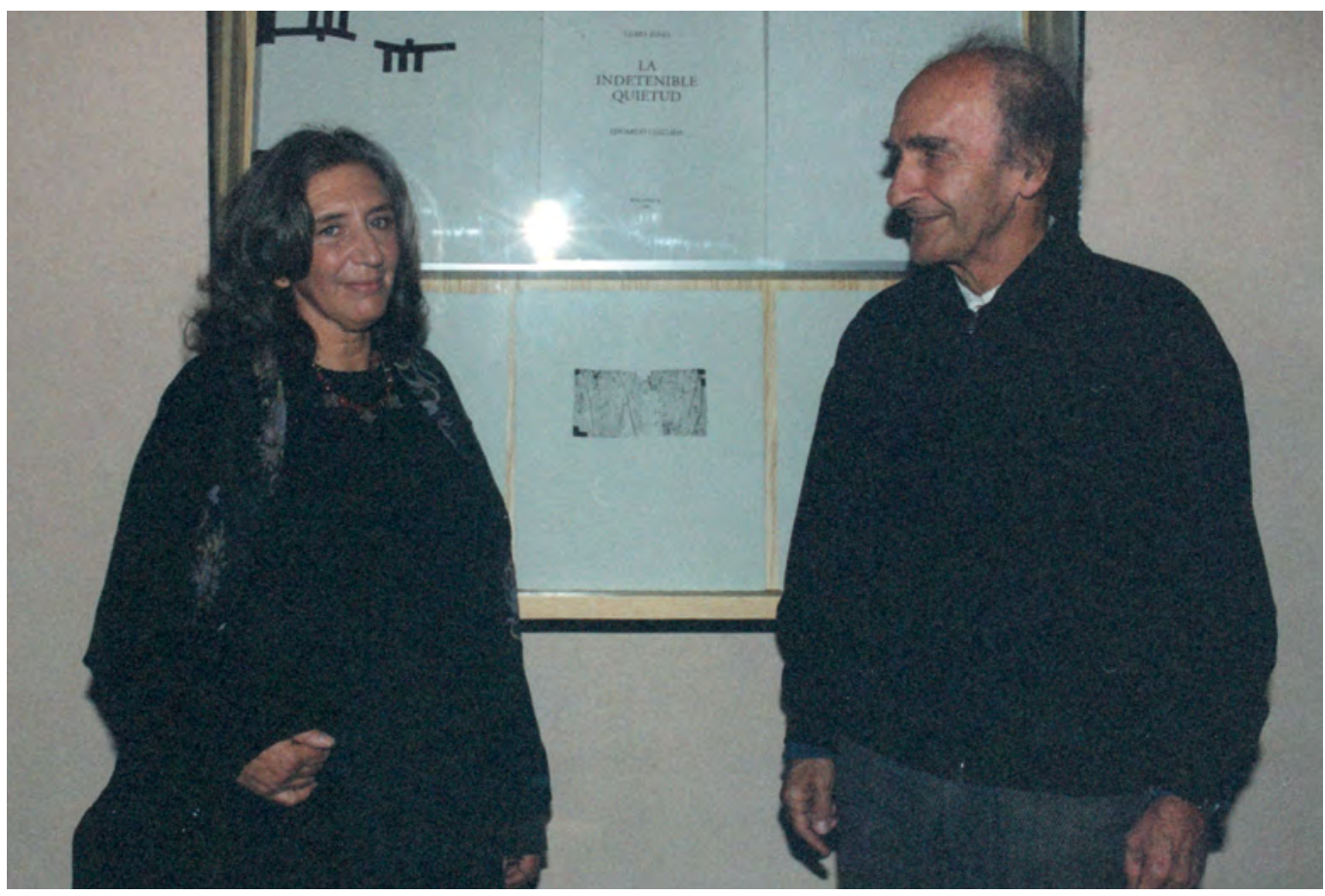

ellas podía darse que solo se detectara el relieve. Santiago Amón comenta este hecho al hablar del libro que llevó a cabo el escultor vasco con el bardo vallisoletano:

Tan razonable se me ocurre la aceptación del blanco sobre blanco por parte de Chillida, de cara a la evidencia del verso de Guillén, y tan consecuente con la imagen primordial (blanca, invisible e inefable plenitud de mediodía) de la poética guilleniana, que más de un pasaje de Cántico valdría para testimoniar la adecuación ejemplar o viva comunión entre el decir del poeta y el arte del grabar a manos del escultor. Sirva este [ejemplo] por otros muchos [y cita tres versos]: «Entre un rigor de rayas / que al mediodía / ciñen de exactitud». [Y continúa Santiago Amón:] ¡Riguroso el filo y el discurso de estas rayas, exacto y evidente a la luz de un mediodía sin riberas! En verdad que ya no sabemos si este concierto de rayas y claridades proviene de un grabado, blanco sobre blanco, de Eduardo Chillida o de un verso o pasaje, pleno sobre pleno, de Jorge Guillén.

(Amón, 1974)

Bellísimo y concorde fue el resultado de la confluencia de ambos creadores, esa concreción en libro a la que se refiere Santiago Amón, porque la escritura de Guillén bien podría incorporar estas palabras de Chillida:

\begin{abstract}
$\mathrm{Al}$ alba conocí la obra, puede ser de mil maneras, pero sólo de una.

Su lugar entre la percepción y la libertad, su huella por identificar, su motivo, la necesidad y su fin, acuerdo².
\end{abstract}

Guillén era un poeta del amanecer. Se trata de la primera luz en un espacio en espera. ¿Vacío? Sobre esta cuestión dice Kosme de Barañano (69):

«Desde los griegos el problema del espacio se planteó al hilo de la oposición entre lo lleno - y lo vacío-.

En la escultura actual el concepto de vacío ha ocupado la mayor parte de sus reflexiones; pero ya no es el vacío democriteano. Ahora el vacío está dimensionado por espacios no creados, no es el éter o el aire en general, es un vacío vivo como el 'silencio que sucede a los acordes no tiene nada que ver con un silencio corriente: es un silencio atento, es un silencio vivo' (Yourcenar)».

Por este estar vivo del silencio surge el sonido. Y la música, que se desarrolla como veíamos en el tiempo,

\footnotetext{
${ }^{2}$ Del texto de la conferencia pronunciada por Eduardo Chillida en el Trinity Collage de Dublín, el año 1988 (Ugarte, 104).
} 
igual y distinta a sí misma, se presenta como un recomenzar. Ya lo hemos dicho, para Chillida, se concreta en un nombre: Juan Sebastián Bach.

Me parece tan próximo al pensamiento de Chillida lo que escribe el portugués Pedro Eiras, en su obra Bach (77), que extraigo un fragmento del capítulo dedicado a Gottfried Wilhelm Leibnitz. Dice:

\section{Tengo frío.}

Saco la pluma del tintero, escribo en la hoja:

Cada alma conoce el infinito, lo conoce todo, pero confusamente; al pasearme por la orilla del mar, y oyendo el gran ruido que hace, oigo los ruidos particulares de cada ola, cuyo sonido total es compuesto, pero sin discernirlos; pero estas percepciones confusas son el resultado de las impresiones que causa en nosotros todo el universo..

Dejo la pluma. ¿Será en verdad así? Pues no discernimos el sonido de cada gota caer sobre las arenas; pero el ruido de la ola no es más que el ruido de todas las gotas de la ola.

Bebo té. Expiro, y sigo la nube de vapor que sale desde mi boca.

Del mismo modo que las olas, también el sonido de la nieve cayendo sobre los marcos, y el sonido del vapor que expiro y se deshace en el aire. Pues esa música compuesta es perceptible, aunque yo no sepa discernir cada parte. Y así oímos pero somos sordos, percibimos el universo y somos ciegos.

Y Vladimír Jankélévitch, en La música y lo inefable (117), afirma, a su vez: «La música profunda es como una naturaleza rica de la que no se aprecian la personalidad y los bienes al paso del mediodía [...] No hay profundidad insondable, sino una inagotable, incansable, inconsumible posibilidad de emoción».

La poesía es música. Música y metáfora y símbolo y movimiento y sugerencia y adivinación es la de san Juan de la Cruz, al que Chillida dedicó distintos homenajes. San Juan decía de sus versos: «más parecen dislates que dichos en razón». Y lo decía porque su simbolismo, apoyado en la melodía de la estrofa, abre la puerta a una plenitud de significados y emociones. Por ello embarga. Quien lee su Cántico capta todo esto sin que pase a su consciente. Quien lo ha escrito, en el momento de enunciarlo tampoco sabía plenamente por qué le acontecía.

En una entrevista con Víctor Gómez Pin (1994, p. 589-593), Chillida recuerda a Huxley y su obra Las puer- tas de la percepción, donde indica que «lo que diferencia al artista [es]: un mayor grado de percepción», al cual da el nombre de «preconocimiento», y dice concretamente: «Hay una cierta manera de conocer - previa a lo que llamamos conocimiento- desde la cual es posible, sin saber cómo es una cosa, conocerla. Esta manera de conocer es tan abierta que admite diversas formas, sin que por eso todavía se sepa cómo es. / Este preconocimiento o aroma es mi guía en lo desconocido, en lo deseado, en lo necesario». Y yo añado: éste es, precisamente, el modo de la poesía.

Atento, pues, está Chillida — como lo estuvo san Juan - para captar lo visible y lo invisible y emprender el movimiento hacia; para seguir la llamada.... Y el mar, queda claro, es uno de sus maestros. Ahora bien, ese lenguaje que está más allá de los conocimientos, ¿cómo se aprehende? Sin duda gracias a estas puertas a lo exterior que son los sentidos. El que de verdad está alerta detecta más de lo que percibe, y no necesita que se le haga claro. Del mismo modo que San Juan de la Cruz cuando habla de las virtudes del pájaro solitario no necesita conocer las cualidades del ave mítica persa Simorg — que son prácticamente las mismas_, tampoco Chillida, cuando, en un espléndido documental cinematográfico llevado a cabo por su hija Susana ${ }^{3}$, se pregunta por el espíritu y no tiene respuesta pero está seguro de que «es más rápido que cualquier otra cosa que hay en la tierra», no precisa haber leído en las Upanishad que «el espíritu es el más veloz de los pájaros». Por su parte los autores de las Upanishad no conocían la teoría de los cuanta y, en cambio, explicaron el universo en último extremo como algo que se hace y se deshace constantemente, representándolo por medio del dios Shiva, proceso que veían a tal velocidad que se avecindaban mucho al concepto de las partículas elementales que, nos dicen, son condensaciones o tendencias, y su ser consiste sólo en estar a punto de llegar a ser. ¿Dónde situamos, llegado este punto, el tiempo y el espacio? Con todo, no dejamos de estar en el movimiento, en la vida...

Documental Chillida, el arte y los sueños, guión y dirección de Susana Chillida, La Bahía, Centro Audiovisual con la colaboración de Canal Plus, 1998. 
Víctor Gómez Pin escribe: «En un texto muy poco conocido dedicado a Eduardo Chillida, el epistemólogo francés Gaston Bachelard lo designa mediante la expresión 'le forgeron', el herrero. [...] el trabajador de Hernani ("trabajé siempre como un burro" solía decir) se sentía permanentemente acosado por un "exceso de preguntas con respecto al espacio". Pero el exceso de preguntas acuciaba también a Arquímedes, y a Euclides y a Descartes y a Riemann y a Einstein. Pensadores estos últimos con los que Eduardo Chillida tenía sorprendentes puntos de convergencia: concretamente en lo referente a la curvatura del espacio mismo y por consiguiente a la imposibilidad de que se dé una superficie de inscripción que coincida con el plano euclidiano ("todo plano es revirado", decía al respecto Chillida en una tan ingenua como precisa expresión)» (Gómez Pin, 2003). Creo que Gómez Pin acertaba plenamente.

\section{Bibliografía}

Amón, Santiago. Eduardo Chillida, Martin Heidegger, Jorge Guillén. Madrid: Galería Turner, 1974.

Bachelard, Gaston. Poética del espacio. México: FCE, 1986.

Barañano, Kosme María. «Sobre el silencio del abismo». Chillida-Heidegger-Husserl. El concepto de espacio en la filosofía y la plástica del siglo XX. Bilbao: Universidad del País Vasco, 1990.

Chamorro Romero, Eduardo. «Chillida: yunque de sueños». Simposium APM, noviembre de 1999.

Eiras, Pedro. Bach. Lisboa: Assírio \& Alvim, 2014.

Fernández Ordóñez, José Antonio. Domande. Preguntas. Milán: All’insegna del pesce d'oro, 1997.

Gómez PIN, Víctor. «Diálogo con Eduardio Chillida y René Thom ante el espacio... pliegues y frunces». Actas del primer Congreso Internacional de Ontología. Barcelona: UAB, 1994.

— «Del "poema" de Parménides a la curvatura del espacio (motivos filosóficos y motivos científicos en el trabajo de Eduardo Chillida». Homenaje a Eduardo Chillida (1924-2002). Bilbao: UPV/EHU, Curso R.1. U. del País Vasco, 18/20 de agosto de 2003.

Heiddeger, Martin. Arte y poesía. México: Fondo de Cultura Económica, 1958.

JAnKÉLÉvitch, Vladimír. Barcelona: Ediciones Alpha Decay, 2005.

LLEDÓ, Emilio. Fidelidad a Grecia. Valladolid: Cuatro ediciones, 2015.

RABE, Ana María. «El arte y la tierra en Martin Heidegger y Eduardo Chillida». Arte, Individuo y Sociedad, 14, 2002.

Ugarte, Luxio. Chillida: dudas y preguntas. Donostia: Erein, 1994. 
